\title{
A Defected Structure Shaped CPW-Fed Wideband Microstrip Antenna for Wireless Applications
}

\author{
Puneet Khanna, ${ }^{1}$ Amar Sharma, ${ }^{1}$ Kshitij Shinghal, ${ }^{2}$ and Arun Kumar ${ }^{1}$ \\ ${ }^{1}$ Electronics and Communication Engineering Department, SET, IFTM University, Moradabad 244001, India \\ ${ }^{2}$ Electronics and Communication Engineering Department, MIT, Moradabad 244001, India \\ Correspondence should be addressed to Puneet Khanna; puneetkhanna2k2@gmail.com
}

Received 28 November 2015; Revised 24 January 2016; Accepted 24 January 2016

Academic Editor: Karim Kabalan

Copyright (c) 2016 Puneet Khanna et al. This is an open access article distributed under the Creative Commons Attribution License, which permits unrestricted use, distribution, and reproduction in any medium, provided the original work is properly cited.

\begin{abstract}
A coplanar waveguide- (CPW-) fed compact wideband defected structure shaped microstrip antenna is proposed for wireless applications. Defected structure is produced by cutting the $\mathrm{U}$ shape antenna in the form of two-sided T shape. The proposed antenna consists of two-sided $\mathrm{T}$ shape strip as compared to usual monopole patch antenna for minimizing the height of the antenna. The large space around the radiator is fully utilized as the ground is on the same plane as of radiator. Microstrip line feed is used to excite the proposed antenna placed on an FR4 substrate (dielectric constant $\varepsilon_{r}=4.4$ ). The antenna is practically fabricated and simulated. Simulated results of the proposed antenna have been obtained by using Ansoft High-Frequency Structure Simulator (HFSS) software. These results are compared with measured results by using network analyzer. Measured result shows good agreement with the simulated results. It is observed that the proposed antenna shows a wideband from $2.96 \mathrm{GHz}$ to $7.95 \mathrm{GHz}$ with three bands at $f_{1}=3.23 \mathrm{GHz}, f_{2}=4.93 \mathrm{GHz}$, and $f_{3}=7.04 \mathrm{GHz}$.
\end{abstract}

\section{Introduction}

Earlier, a number of studies used different antenna structures to design wideband microstrip patch antenna. However, the dimension of antenna is a very challenging task especially in the case of ground structure $[1-3]$.

The familiar structure of $\lambda / 4$ single antenna radiator gives wideband. All the researchers have focused on the shrinking of monopole antenna size. Most of the designs are facing the shortcomings of the monopole antenna such as large ground area, height of antenna radiator, and the space around the antenna radiator [4-6]. Design of simple, compact, and multipurpose antenna is an important aspect in the integration of wideband system with moveable devices so that it can reduce the difficulty of the transmitter and receiver of the system [7]. Various shapes of microstrip antennas have been used for compact wideband antenna. Some of them are as butterfly shape [8], inverted cone slot [9], tapered slot with tuning patch [10], inverted L-strip slot [11], LTCC technology [12], triple layer double $U$ shape slot [13], inverted U shape slot [14], and many other shapes [15].

The present paper presents a minute study of coplanar waveguide- (CPW-) fed compact wideband antenna that is proposed and designed. The antenna is composed of a radiating patch having good radiation ranges from 2.96 to $7.95 \mathrm{GHz}$ with an impedance bandwidth of $91.47 \%$. The proposed antenna uses two-sided $\mathrm{T}$ shape strip over the conventional radiator patch antenna for reducing the height of the antenna. The ground is also on the same plane as of radiator so that the large space around the radiator is fully utilized. The advantage of proposed antenna is that it covers wide range of frequency while single band antenna requires installation of two or more antennas for the same purpose at the same location that creates complexity. The proposed structure of the antenna is shown in Figure 1. The next section deals with antenna designing technique, in detail. Section 3 covers experimental results and its discussion. Section 4 concludes all the discussion made earlier.

\section{Antenna Design}

The design of the two-sided T shape proposed antenna has been shown in Figure 1. The proposed antenna design is chosen to generate three resonant bands for achieving wide bandwidth. It consists of two-sided $\mathrm{T}$ shape strip and two 
TABLE 1: Proposed antenna design parameters.

\begin{tabular}{lcccccccc}
\hline Parameters & $L_{p 1}$ & $L_{p 2}$ & $L_{p 3}$ & $L_{p 4}$ & $L_{g 1}$ & $L_{g 2}$ & $L_{p d}$ & $L_{r}$ \\
\hline Unit $(\mathrm{mm})$ & 3 & 7 & 2 & 6.6 & 8 & $W_{g 2}$ & $W_{g 3}$ & 0.8 \\
\hline Parameters & $W_{p 1}$ & $W_{p 2}$ & $W_{p 3}$ & $W_{g 1}$ & $W_{f}$ & $h$ \\
\hline Unit $(\mathrm{mm})$ & 2.5 & 2.5 & 5 & 10.6 & 4 & 1 & 1.5 & 1.6 \\
\hline
\end{tabular}

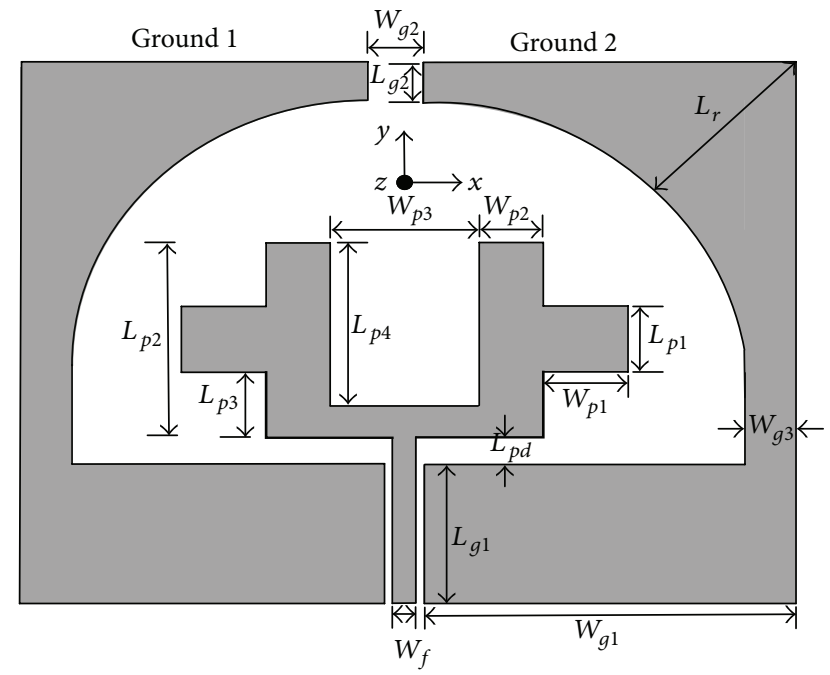

(a)

(b)

FIGURE 1: Schematic configuration of the proposed CPW-fed twosided T strip wideband microstrip antenna.

grounds placed on the same plane as of radiator fed by CPW. The antenna is fabricated and printed on an FR4 substrate having relative permittivity $\varepsilon_{r}=4.4$, thickness $h=1.6 \mathrm{~mm}$, and loss $\operatorname{tangent} \tan \delta=0.024$. The overall size of the antenna is $25 \times 25 \times 1.6 \mathrm{~mm}^{3}$. The electromagnetic solver, Ansoft HFSS [16], is used to investigate and optimize the dimensions of the proposed design on the basis of best performance. The width of the CPW feed line is fixed at $1.5 \mathrm{~mm}$ to achieve $50 \Omega$ characteristic impedance. While the radiator is bounded by a metal ground plane for reducing the antenna area, the small gap between the radiator and the ground plane causes capacitive coupling. This type of design is introduced to obtain wideband with good impedance matching over the entire band. The base of the monopole radiator is a rectangular $U$ shape having dimensions of length $L_{p 2}$ and width $W_{p 3}$ which is further converted into two-sided T shape by connecting two strips on both the sides with dimensions of length $L_{p 1}$ and width $W_{p 1}$ having a distance of $L_{p 3}$ from the base of rectangular $U$ shape.

The ground planes are embedded from the patch's left and right sides on the same plane to provide the CPW feed. The proposed antenna having dimensions listed in Table 1 are used to obtain wideband and better return loss along with an efficiency of $91.47 \%$. A photograph of the fabricated antenna is shown in Figure 2. Figure 3 trace (iii) shows the

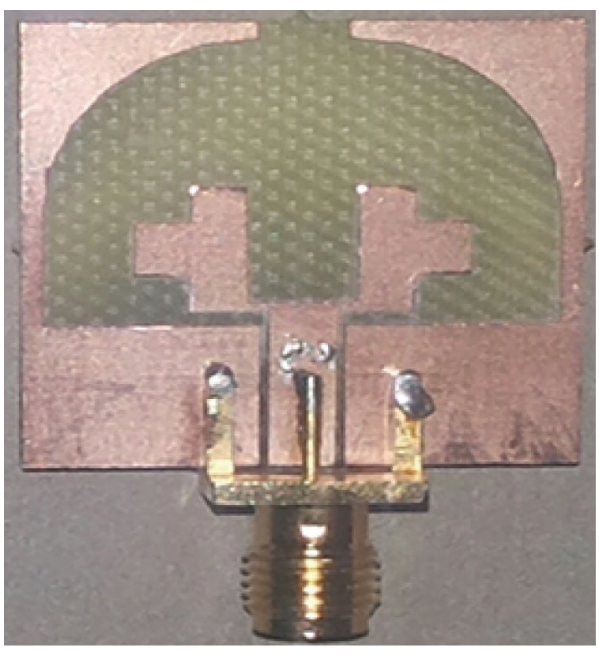

FIGURE 2: Photograph of the fabricated CPW-fed two-sided T strip wideband microstrip antenna.

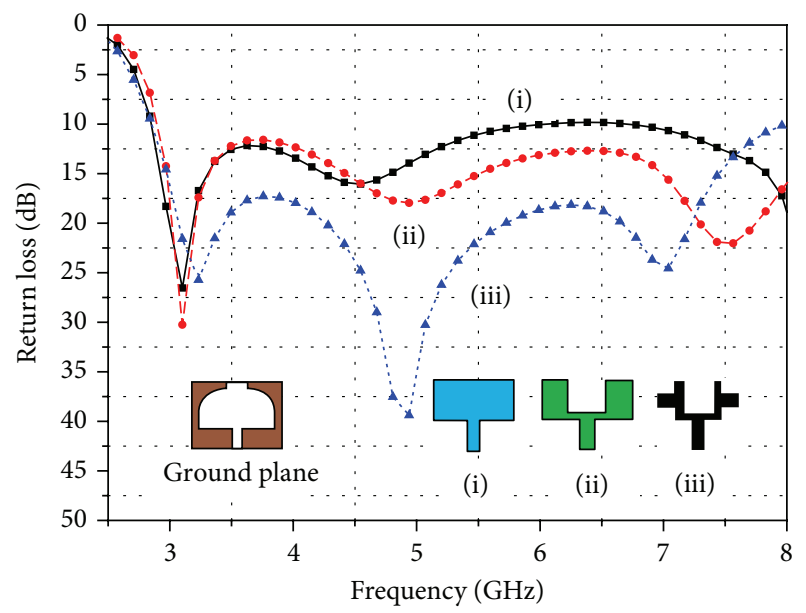

FIGURE 3: Simulated return loss against frequency for the rectangular antenna, rectangular U shape antenna, and proposed CPW-fed two-sided T strip wideband microstrip antenna.

simulated return loss of the proposed antenna. Simulated results show wide bandwidth from 2.96 to $7.95 \mathrm{GHz}$. Initially the rectangular patch was tested for wide bandwidth shown in Figure 3 trace (i), and then the radiator shape was further modified to rectangular $U$ shape shown in Figure 3 trace (ii). In both these cases worst return loss appears over the entire frequency band with a single resonant band at about $3.23 \mathrm{GHz}$. As for the case of the proposed design of two-sided $\mathrm{T}$ shaped antenna Figure 3 trace (iii) improves the impedance 


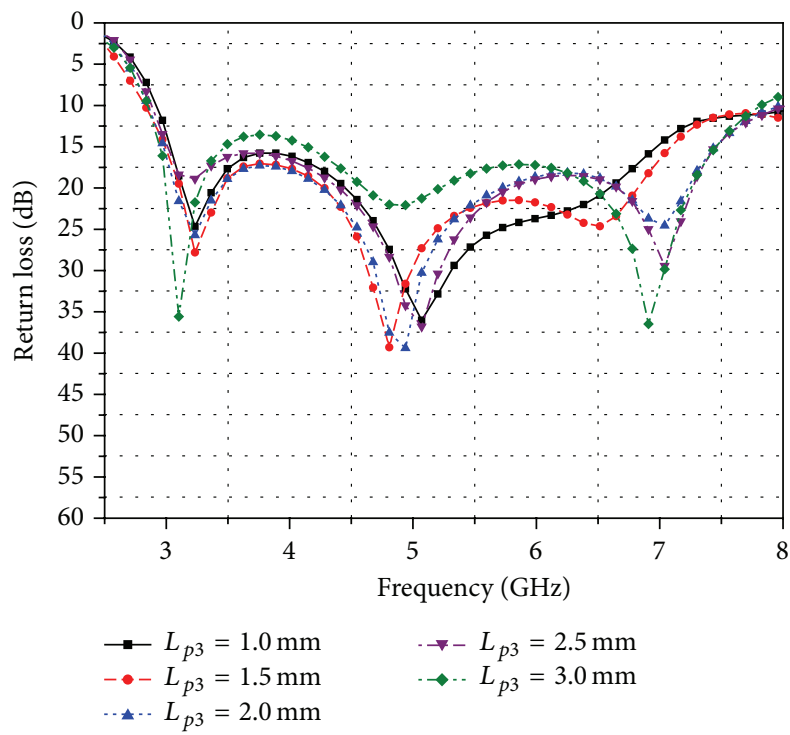

FIGURE 4: Simulated return loss against frequency for the proposed CPW-fed two-sided $\mathrm{T}$ strip wideband microstrip antenna with various values of $L_{p 3}$; other parameters are the same as listed in Table 1.

matching conditions for the entire band and shows three resonant bands $f_{1}=3.23 \mathrm{GHz}, f_{2}=4.93 \mathrm{GHz}$, and $f_{3}=$ $7.04 \mathrm{GHz}$, respectively. Note that, in all these three cases, the ground structure is the same as shown in Figure 3, while all the unspecified dimensions are the same as listed in Table 1.

2.1. Variation of $\mathrm{T}$ Strip Parameters. Figure 4 shows the simulated results of the proposed antenna with T strip length $L_{p 3}$ that varies from 1.0 to $3.0 \mathrm{~mm}$. On increasing the length of $L_{p 3}$, it was observed that with increase of length the radiating patch shows increase in bandwidth and also increase in the resonant bands $>10 \mathrm{~dB}$ for every change in length. The patch shows the wide bandwidth except for $1.0 \mathrm{~mm}$ and $1.5 \mathrm{~mm}$. The return loss with three resonant bands $>10 \mathrm{~dB}$ comes in the case when $L_{p 3}=2.0 \mathrm{~mm}$ while at resonant band $f_{2}=$ $4.93 \mathrm{GHz}$ it shows the maximum return loss and covers the whole band. Therefore it is decided to take $L_{p 3}=2.0 \mathrm{~mm}$ as the optimum length, to get wide bandwidth from 2.96 to $7.95 \mathrm{GHz}$.

The simulated results of the proposed antenna with the patch width $W_{p 1}$ is shown in Figure 5. $W_{p 1}$ varies from $1.5 \mathrm{~mm}$ to $3.5 \mathrm{~mm}$. It was observed that the return loss $<10 \mathrm{~dB}$ with three resonant bands is achieved only at $W_{p 1}=2.5 \mathrm{~mm}$; for other values of $W_{p 1}$ it was found out that they do not cover up the entire wideband with three resonant bands with greater return loss. Therefore it is decided to take $W_{p 1}=2.5 \mathrm{~mm}$ as the optimum patch width, resulting in the bandwidth from 2.96 to $7.95 \mathrm{GHz}$.

\subsection{Variation of Centre Part of Rectangular Slot Parameters.} Figure 6 shows the simulated result of the proposed antenna with the variation of the centre part of rectangular slot length $L_{p 4}$. The length of $L_{p 4}$ varies from 6.5 to $6.7 \mathrm{~mm}$. The result

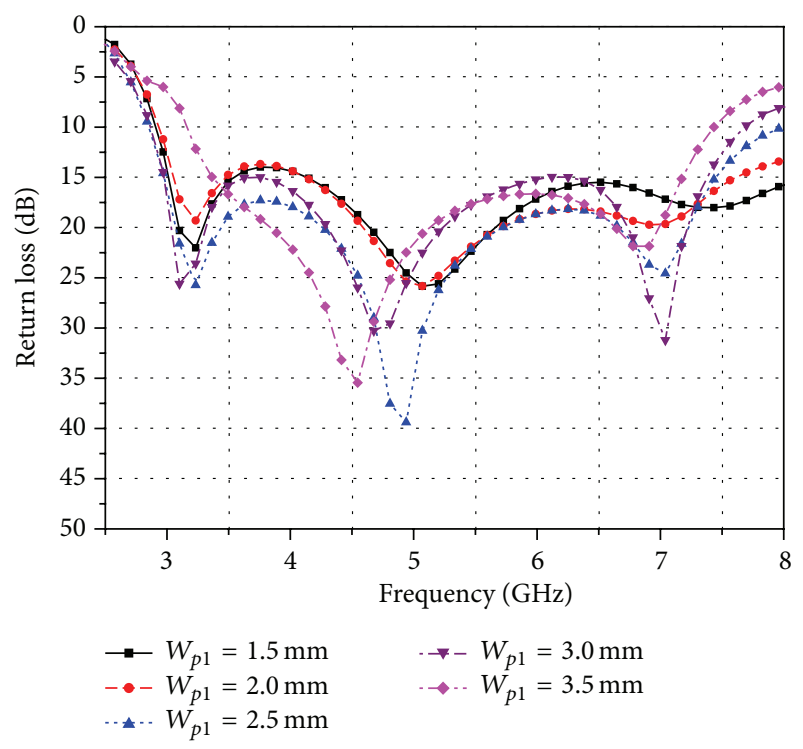

FIGURE 5: Simulated return loss against frequency for the proposed CPW-fed two-sided T strip wideband microstrip antenna with various values of $W_{p 1}$; other parameters are the same as listed in Table 1.

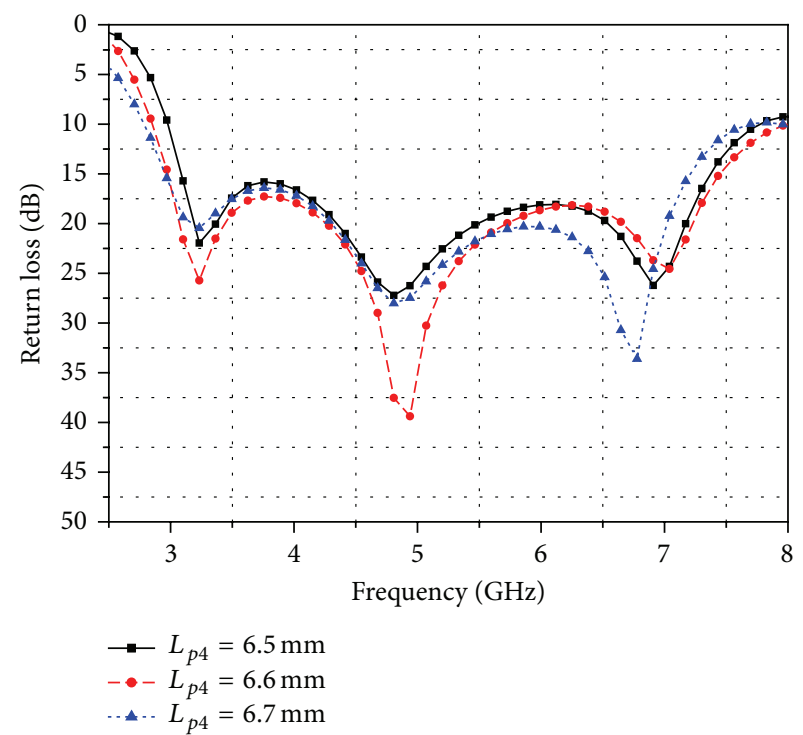

FIGURE 6: Simulated return loss against frequency for the proposed CPW-fed two-sided $\mathrm{T}$ strip wideband microstrip antenna with various values of $L_{p 4}$; other parameters are the same as listed in Table 1.

shows that for all lengths the return loss is $>10 \mathrm{~dB}$ which covers the whole band, but for resonant bands $f_{1}=3.23 \mathrm{GHz}$ and $f_{2}=4.93 \mathrm{GHz}$ the maximum return loss was obtained when $L_{p 4}=6.6 \mathrm{~mm}$. Therefore it is decided to take $L_{p 4}=$ $6.6 \mathrm{~mm}$ as the optimum length for the use in the proposed antenna.

2.3. Variation of Microstrip Feed Parameters. Figure 7 shows the simulated result of the proposed antenna with the 
TABLE 2: Comparison between the proposed antenna and some existing wideband microstrip antenna.

\begin{tabular}{|c|c|c|c|c|c|c|c|}
\hline Reference & $\begin{array}{l}\text { Antenna } \\
\text { type }\end{array}$ & $\begin{array}{c}\text { Overall } \\
\text { dimension } \\
\left(\mathrm{mm}^{3}\right)\end{array}$ & $\begin{array}{c}\text { Frequency } \\
\text { range }(\mathrm{GHz})\end{array}$ & $\begin{array}{c}\text { Fract. } \\
\text { bandwidth } \\
(\%)\end{array}$ & $\begin{array}{l}\text { Maximum } \\
\text { gain }(\mathrm{dBi})\end{array}$ & $\begin{array}{c}\text { Relative } \\
\text { dielectric } \\
\text { constant, } \varepsilon_{r}\end{array}$ & Application \\
\hline [1] & Wideband & $60 \times 30 \times 1.6$ & $1.2-4.5$ & 142 & 2.2 & 4.4 & General \\
\hline [17] & UWB & $29 \times 31 \times 1.6$ & $3.0-10.6$ & 111 & 5.5 & 4.4 & UWB \\
\hline [18] & Wideband & $30 \times 31 \times 1.6$ & $3.8-5.5$ & Not given & 10.8 & 4.4 & $\begin{array}{c}\text { WLAN and } \\
\text { WiMAX }\end{array}$ \\
\hline [19] & Dual band & $30 \times 30 \times 1.58$ & $\begin{array}{c}1.86-1.97 \\
3.0-12.0\end{array}$ & 52,120 & 5 & 4.4 & $\begin{array}{l}\text { PCS and } \\
\text { UWB }\end{array}$ \\
\hline [20] & Wideband & $38 \times 25 \times 1.6$ & $2.4-6.0$ & 86.71 & 2.85 & 4.4 & $\begin{array}{l}\text { WLAN, } \\
\text { WiMAX }\end{array}$ \\
\hline Proposedantenna & Wideband & $25 \times 25 \times 1.6$ & $2.96-7.95$ & 91.47 & 7.3 & 4.4 & $\mathrm{~S}$ and $\mathrm{C}$ band \\
\hline
\end{tabular}

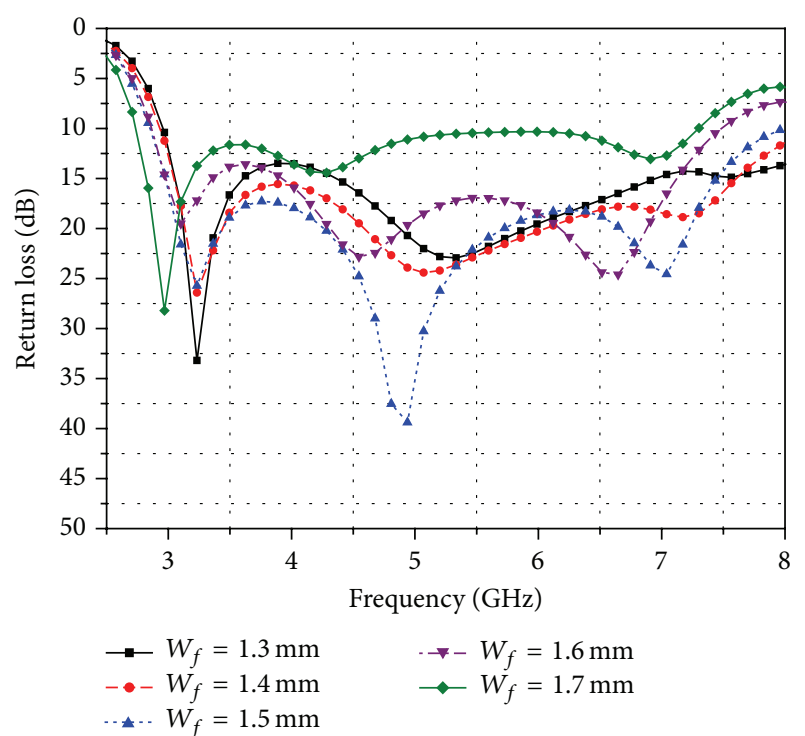

FIGURE 7: Simulated return loss against frequency for the proposed CPW-fed two-sided $\mathrm{T}$ strip wideband microstrip antenna with various values of $W_{f}$; other parameters are the same as listed in Table 1.

variation of the feed width $W_{f}$. The width $W_{f}$ varies from $1.3 \mathrm{~mm}$ to $1.7 \mathrm{~mm}$. The result shows that with the increase in feed width the resonant bands increase up to the value of $W_{f}=1.5 \mathrm{~mm}$. For more than $1.5 \mathrm{~mm}$ value of $W_{f}$ the bandwidth decreases. Therefore we took $W_{f}=1.5$ as the optimum feed width, resulting in the bandwidth from 2.96 to $7.95 \mathrm{GHz}$.

\section{Experimental Results and Discussion}

An Agilent 8757E scalar network analyzer was used to measure the performance of the proposed antenna such as return loss. Figure 8 shows the measured and simulated return loss curves of the two-sided $\mathrm{T}$ shape wideband antenna. There is a balanced agreement in measured and simulated results that is shown in Figure 8. The small difference between the measured and simulated result is due to the effect of SMA (subminiature version A) connector soldering and

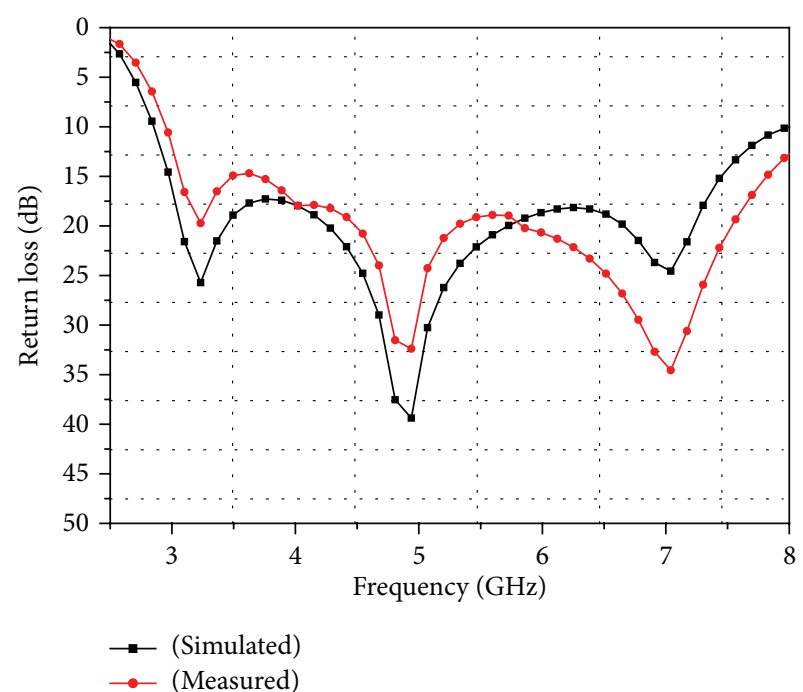

FIGURE 8: Measured and simulated return loss for the proposed CPW-fed two-sided T strip wideband microstrip antenna.

fabrication tolerance. The designed antenna has a wide bandwidth performance from 2.96 to $7.95 \mathrm{GHz}$ with three resonant bands at $f_{1}=3.23 \mathrm{GHz}, f_{2}=4.93 \mathrm{GHz}$, and $f_{3}=$ $7.04 \mathrm{GHz}$, respectively.

Table 2 shows a comparative study between the proposed antenna and some existing antennas on the basis of wideband CPW structure. The tabulated data clearly shows that the proposed antenna has highest gain among the other antennas having approximate similar dimensions. On the other part, some of the antennas have smaller gain with enhanced bandwidth and dimension. These large size antennas would require more space for installation in portable device which is not a preferable situation.

Figures 9(a)-9(c) show the simulated and measured far field radiation patterns in the $H$ and $E$ planes at frequencies $3.23 \mathrm{GHz}, 4.93 \mathrm{GHz}$, and $7.04 \mathrm{GHz}$. It has been found out that the proposed antenna has nearly good omnidirectional radiation pattern at all frequencies in the $E$ plane and the $H$ plane. As shown in Figure 1(a), the shape of proposed antenna is two-sided $\mathrm{T}$ strip. The proposed antenna has nonregular 

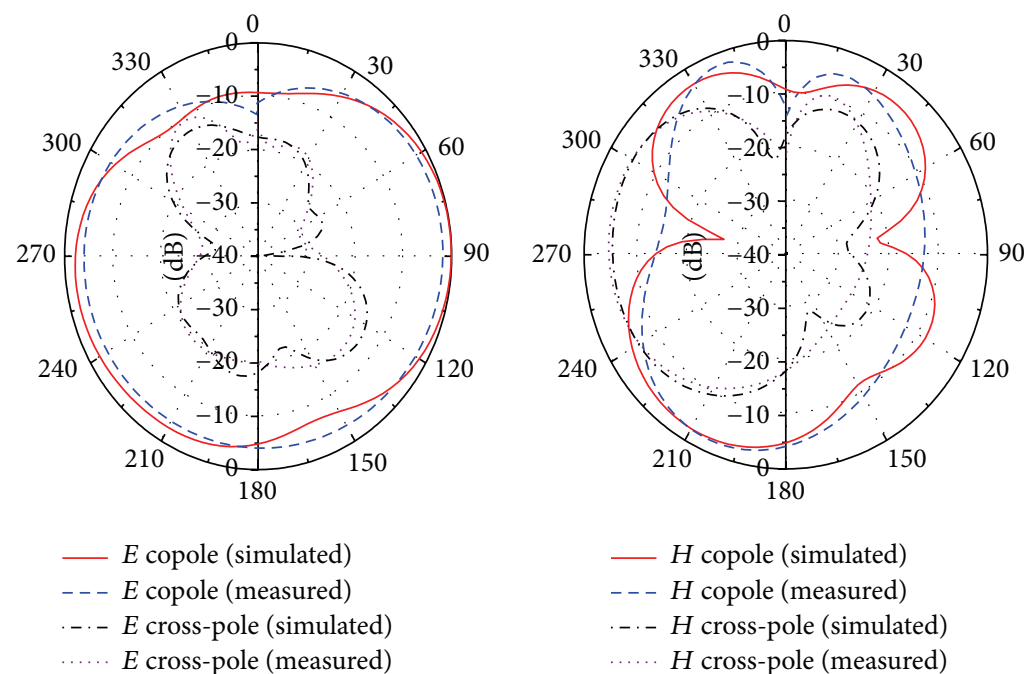

$$
\begin{aligned}
& -H \text { copole (simulated) } \\
& ---H \text { copole (measured) } \\
& .--H \text { cross-pole (simulated) } \\
& \ldots . . H \text { cross-pole (measured) }
\end{aligned}
$$

(a)
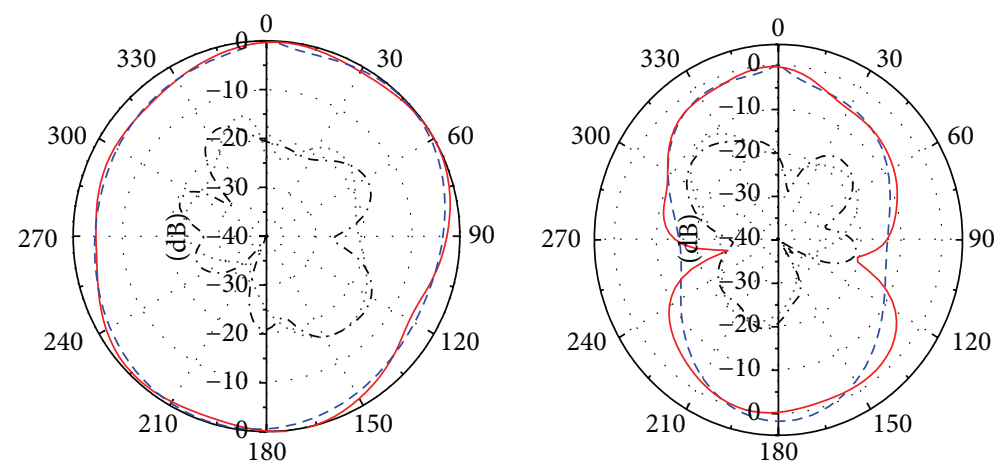

$-E$ copole (simulated)
$---E$ copole (measured)
$--E$ cross-pole (simulated)
$\ldots . . E$ cross-pole (measured)

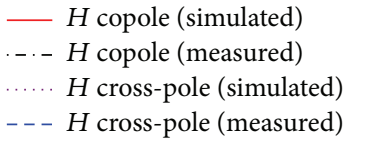

(b)
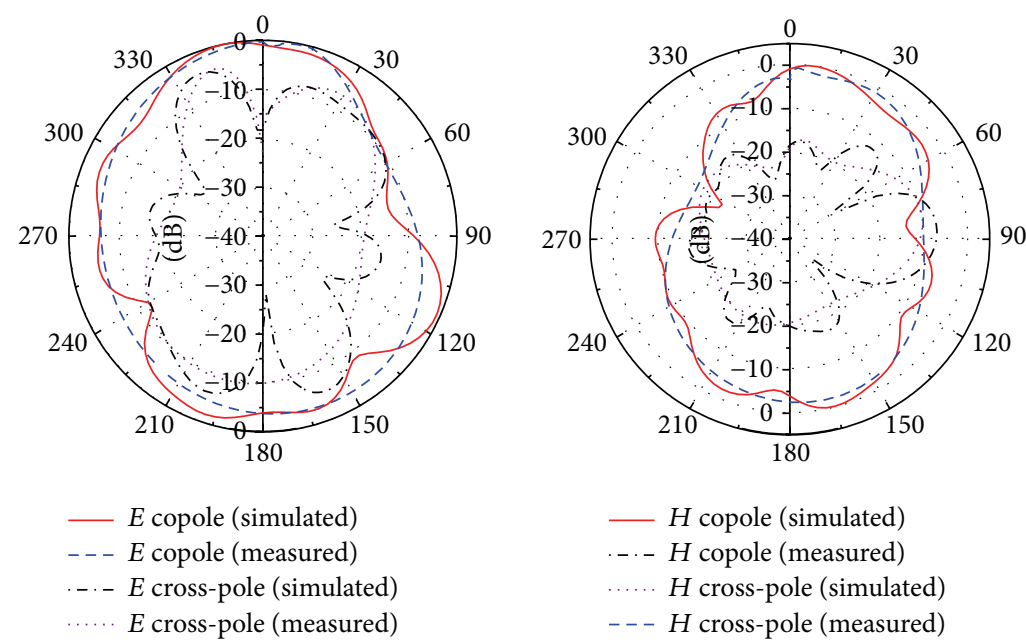

(c)

FIGURE 9: Measured and simulated radiation pattern of various resonance frequencies for the proposed CPW-fed two-sided T strip wideband microstrip antenna (a) at $3.23 \mathrm{GHz}$, (b) $4.93 \mathrm{GHz}$, and (c) $7.04 \mathrm{GHz}$. 


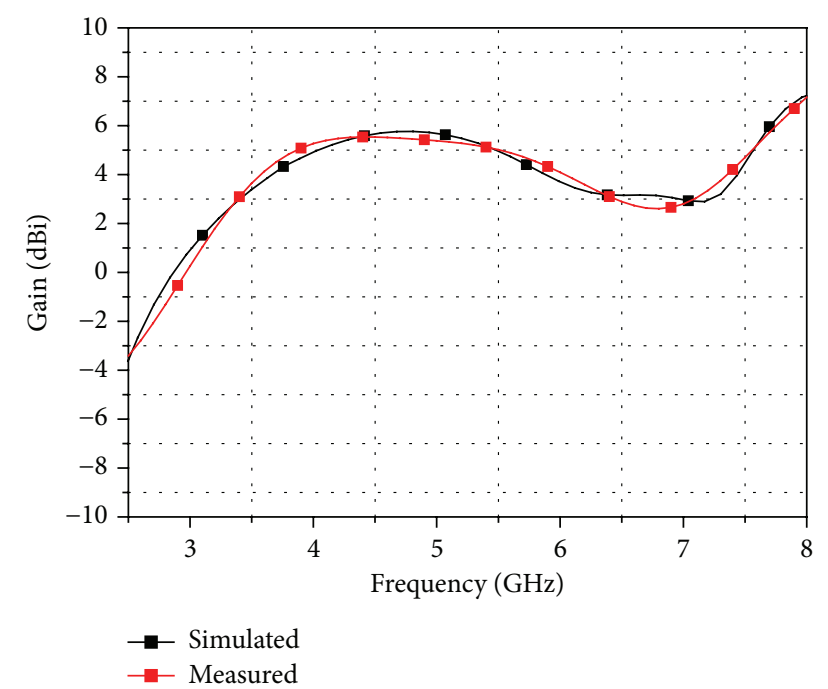

FIGURE 10: Measured and simulated gain for the proposed CPW-fed two-sided T strip wideband microstrip antenna.

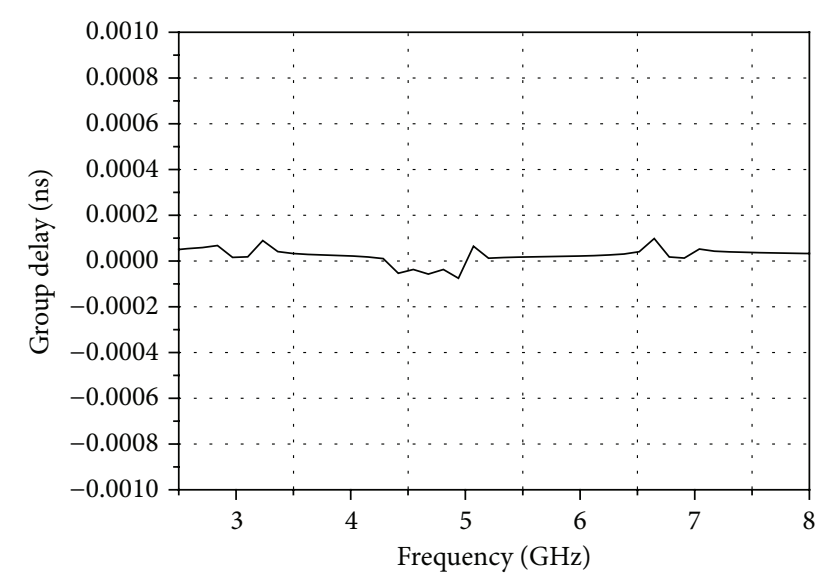

FIGURE 11: Group delay for the proposed CPW-fed two-sided T strip wideband microstrip antenna.

geometric shape. This shape is chosen to get desired wideband and high gain. Due to this nonregular geometry, the radiation pattern of proposed antenna is not smooth, but at all three frequencies $(3.23 \mathrm{GHz}, 4.93 \mathrm{GHz}$, and $7.04 \mathrm{GHz}) 3 \mathrm{~dB}$ beam width is sufficient for all wireless applications.

Gain is an important parameter in the design of wideband antenna. Figure 10 illustrates the simulated and measured gain of the proposed antenna. It was found out that the gain of the antenna varies within 1.5 to $7.3 \mathrm{dBi}$ against the frequency band of 2.96 to $7.95 \mathrm{GHz}$. Group delay is also an important parameter in the design of the wideband antenna because it shows the degree of distortion in transmitted pulses. For good pulse transmission group delay should be less than 0.5 ns. Figure 11 illustrates the group delay of the proposed antenna. It was found out that the variation of the group delay for proposed antenna is almost constant for the entire frequency band of 2.96 to $7.95 \mathrm{GHz}$. This shows that the proposed antenna is suitable for wideband communication.

\section{Conclusion}

The proposed coplanar waveguide- (CPW-) fed compact wideband defected structure shaped microstrip antenna with two-sided T strip is designed and fabricated. The measured result of the fabricated antenna shows omnidirectional radiation pattern over the entire operating bandwidth. Three different resonant bands are obtained at $3.23 \mathrm{GHz}, 4.04 \mathrm{GHz}$, and $7.04 \mathrm{GHz}$ which works on $\mathrm{S}$ and $\mathrm{C}$ band, which are most suitable for various communication systems. The antenna has a wide bandwidth of about $91.47 \%$ in the frequency range from 2.96 to $7.95 \mathrm{GHz}$.

\section{Conflict of Interests}

The authors declare that there is no conflict of interests regarding the publication of this paper.

\section{References}

[1] C.-L. Tsai and C.-L. Yang, "Novel compact eye shaped UWB antennas," IEEE Antennas and Wireless Propagation Letters, vol. 11, pp. 184-187, 2012.

[2] K. G. Thomas and M. Sreenivasan, "A simple ultrawideband planar rectangular printed antenna with band dispensation," IEEE Transactions on Antennas and Propagation, vol. 58, no. 1, pp. 27-34, 2010.

[3] J. A. Ansari, K. Kumari, A. Singh, and A. Mishra, "Ultra wideband co-planer microstrip patch antenna for wireless applications," Wireless Personal Communications, vol. 69, no. 4, pp. 1365-1378, 2013.

[4] H. G. Schantz, "A brief history of UWB antennas," IEEE Aerospace and Electronic Systems Magazine, vol. 19, no. 4, pp. 22-26, 2004.

[5] X. Chen, J. Liang, P. Li, L. Guo, C. C. Chiau, and C. G. Parini, "Planar UWB monopole antennas," in Proceedings of the Asia-Pacific Conference Proceedings Microwave Conference Proceedings (APMC '05), IEEE, December 2005.

[6] M. K. Khandelwal, B. K. Kanaujia, S. Dwari, S. Kumar, and A. K. Gautam, "Analysis and design of wide band Microstripline-fed antenna with defected ground structure for Ku band applications," AEU-International Journal of Electronics and Communications, vol. 68, no. 10, pp. 951-957, 2014.

[7] M. Bod, H. R. Hassani, and M. M. S. Taheri, "Compact UWB printed slot antenna with extra bluetooth, GSM, and GPS bands," IEEE Antennas and Wireless Propagation Letters, vol. 11, pp. 531-534, 2012.

[8] L. Sun, M. He, J. Hu, Y. Zhu, and H. Chen, "A butterfly-shaped wideband microstrip patch antenna for wireless communication," International Journal of Antennas and Propagation, vol. 2015, Article ID 328208, 8 pages, 2015.

[9] S. Cheng, P. Hallbjörner, and A. Rydberg, "Printed slot planar inverted cone antenna for ultrawideband applications," IEEE Antennas and Wireless Propagation Letters, vol. 7, pp. 18-21, 2008.

[10] R. Azim, M. T. Islam, and N. Misran, "Compact taperedshape slot antenna for UWB applications," IEEE Antennas and Wireless Propagation Letters, vol. 10, pp. 1190-1193, 2011.

[11] A. K. Gautam, S. Yadav, and B. K. Kanaujia, "A CPW-Fed compact UWB microstrip antenna," IEEE Antennas and Wireless Propagation Letters, vol. 12, pp. 151-154, 2013. 
[12] X. Qing and Z. N. Chen, "Monopole-like slot UWB antenna on LTCC," in Proceedings of the IEEE International Conference on Ultra-Wideband (ICUWB '08), pp. 121-124, IEEE, Hannover, Germany, September 2008.

[13] N. K. Darimireddy, R. Ramana Reddy, and A. Mallikarjuna Prasad, "Design of triple-layer double U-slot patch antenna for wireless applications," Journal of Applied Research and Technology, vol. 13, no. 5, pp. 526-534, 2015.

[14] L.-N. Zhang, S.-S. Zhong, X.-L. Liang, and C.-Z. Du, "Compact omnidirectional band-notch ultra-wideband antenna," Electronics Letters, vol. 45, no. 13, pp. 659-660, 2009.

[15] P. Khanna, K. Shinghal, and A. Kumar, "A survey of defected wideband and multiband microstrip patch antennas," International Journal for Scientific Research \& Development, vol. 3, no. 4, pp. 2043-2047, 2015.

[16] Ansoft Corporation, Ansoft High-Frequency Structure Simulator (HFSS), version 14.0, Ansoft Corporation, Pittsburgh, Pa, USA.

[17] A. Kumar and T. Shanmuganantham, "A CPW fed octagonal patch UWB antenna with WiMAX band-notched characteristics," in Proceedings of the International Conference on Information Communication and Embedded Systems (ICICES '14), pp. 1-5, Chennai, India, Feburary 2014.

[18] A. Singh and S. Singh, "A novel CPW-fed wideband printed monopole antenna with DGS," AEU-International Journal of Electronics and Communications, vol. 69, no. 1, pp. 299-306, 2015.

[19] R. Kumar, P. Naidu V, and V. Kamble, "A compact asymmetric slot dual band antenna fed by CPW for PCS and UWB applications," International Journal of RF and Microwave ComputerAided Engineering, vol. 25, no. 3, pp. 243-254, 2015.

[20] A. K. Gautam, A. Bisht, and B. Kr. Kanaujia, "A wideband antenna with defected ground plane for WLAN/WiMAX applications," AEU-International Journal of Electronics and Communications, vol. 70, no. 3, pp. 354-358, 2016. 


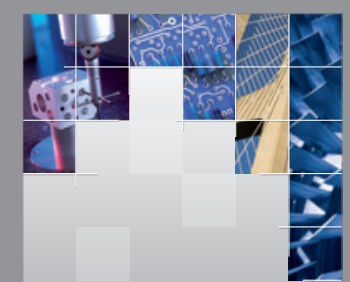

\section{Enfincering}
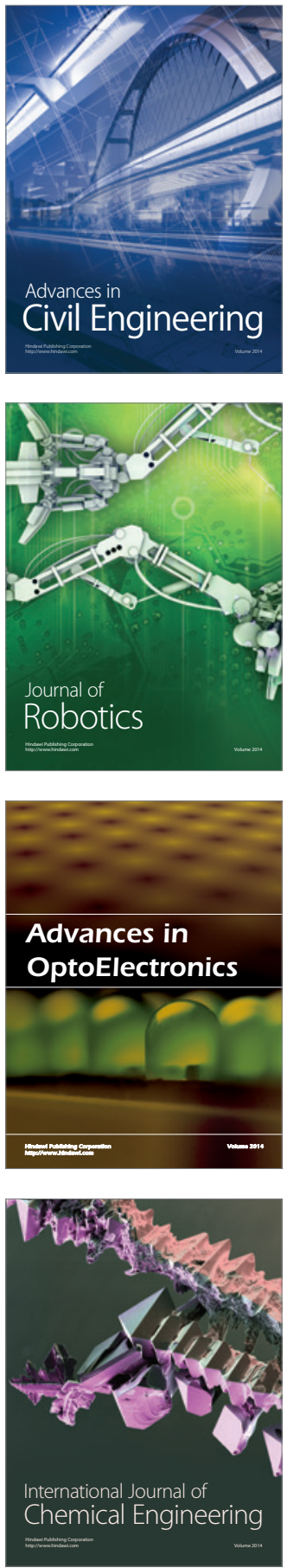

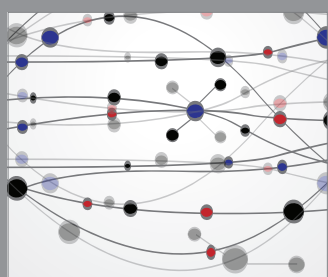

The Scientific World Journal

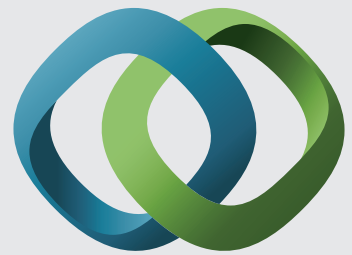

\section{Hindawi}

Submit your manuscripts at

http://www.hindawi.com
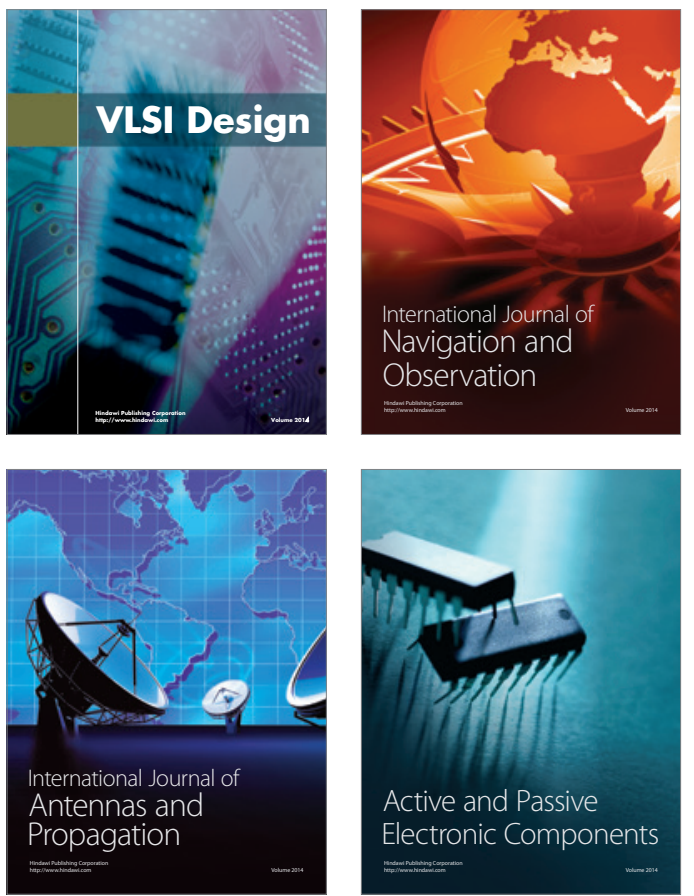
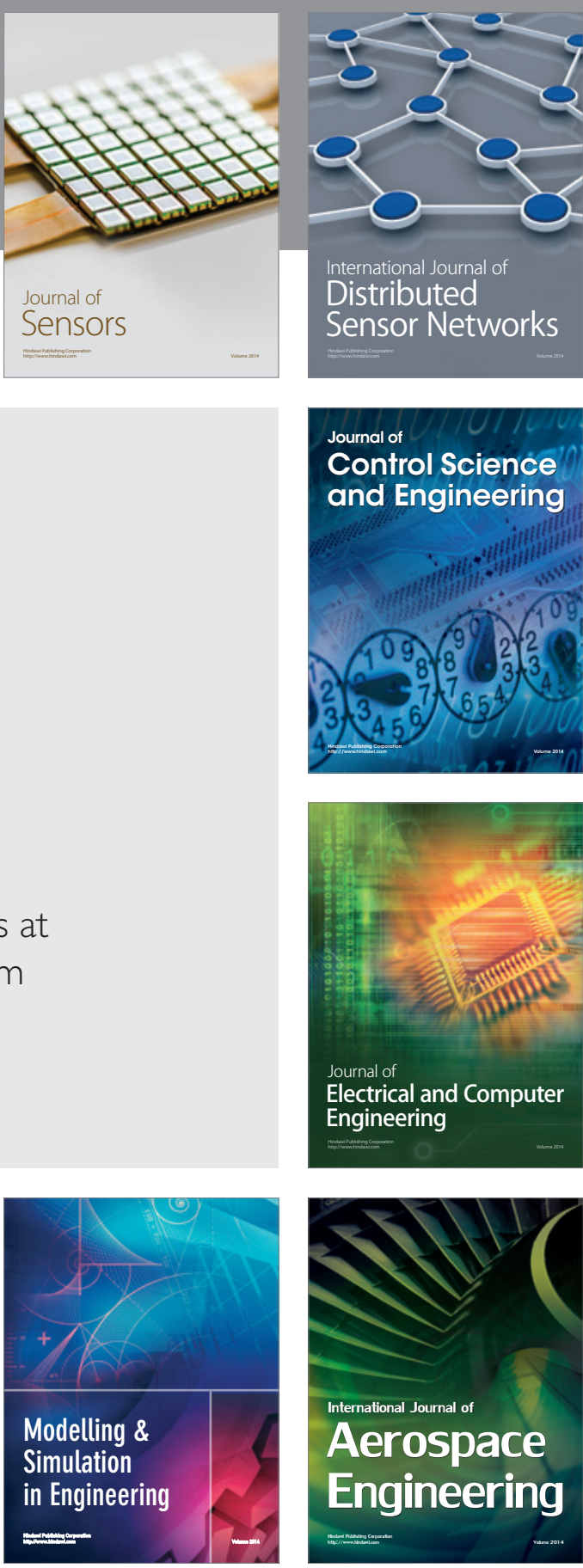

International Journal of

Distributed

Sensor Networks

Journal of

Control Science

and Engineering
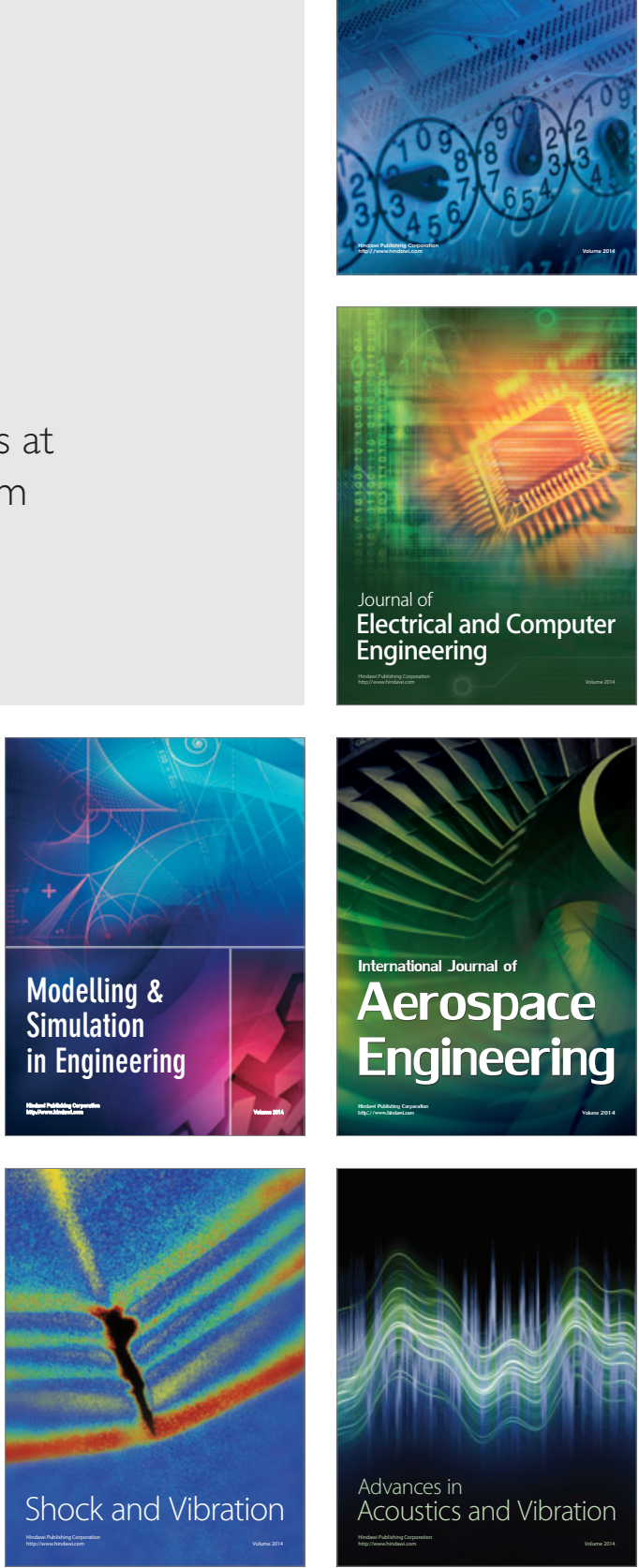